\section{Pacific Northwest}

National Laboratory

Operated by Battelle for the

U.S. Department of Energy

\title{
Sodium Hydroxide Extraction From Caustic Leaching Solutions
}

\author{
G.J. Lumetta \\ P.A. Garza \\ T.G. Levitskaia \\ Pacific Northwest National Laboratory \\ G.M. Brown \\ Oak Ridge National Laboratory
}

September 2002

Prepared for the U.S. Department of Energy under Contract DE-AC06-76RL01830

This work is funded by the Office of Science and Technology, within the Department of Energy's Office of Environment Management, under the Efficient Separations and Processing Crosscutting Program. 


\title{
Sodium Hydroxide Extraction From Caustic Leaching Solutions
}

\author{
G. J. Lumetta \\ P. A. Garza \\ T. G. Levitskaia \\ Pacific Northwest National Laboratory \\ G. M. Brown \\ Oak Ridge National Laboratory
}

September 2002

Prepared for

the U.S. Department of Energy

under Contract DE-AC06-76RL01830

This work is funded by the Office of Science and Technology, within the Department of Energy's Office of Environmental Management, under the Efficient Separations and Processing Crosscutting Program.

Pacific Northwest National Laboratory

Richland, Washington 99352 


\section{Summary}

This report describes experiments conducted to demonstrate the proof-of-principle of a method to recover $\mathrm{NaOH}$ from Hanford tank sludge leaching solutions. Aqueous solutions generated from leaching actual Hanford tank waste solids were used. The process involves neutralization of a lipophilic weak acid ( $t$-octylphenol was used in these experiments) by reaction with $\mathrm{NaOH}$ in the aqueous phase. This results in the transfer of $\mathrm{Na}$ into the organic phase. Contacting with water reverses this process, reprotonating the lipophilic weak acid and transferring $\mathrm{Na}$ back into the aqueous phase as $\mathrm{NaOH}$.

The work described here confirms the potential application of solvent extraction to recover and recycle $\mathrm{NaOH}$ from solutions generated by leaching Hanford tank sludges. Solutions obtained by leaching sludges from Tanks S-110 and T-110 were used in this work. It was demonstrated that $\mathrm{Na}^{+}$is transferred from caustic leaching solution to the organic phase when contacted with $t$-octylphenol solutions. This was accompanied by a concomitant decrease in the aqueous-phase hydroxide ion concentration. Seventy to $80 \%$ of the extracted $\mathrm{Na}$ was recovered by 3 to 4 sequential contacts of the organic phase with water. Cesium was co-extracted by the procedure, but $\mathrm{Al}$ and $\mathrm{Cr}$ remained in the feed stream.

The results of this study revealed several areas that will require further investigation before the technology can be implemented.

- Stripping of $\mathrm{Na}$ from the organic phase. The results of the $\mathrm{T}-110$ test suggested that it might be difficult to get complete recovery of $\mathrm{Na}^{+}$as $\mathrm{NaOH}$ by stripping with water. It may be necessary to employ an acid wash of the solvent to remove residual $\mathrm{Na}^{+}$before the solvent can be recycled in the process.

- Phase-disengagement behavior. Interfacial crud was observed in the S-110 stripping contacts, and cloudy phases were seen during the T-110 stripping contacts. The reasons for these phenomena, and the means to avoid them, need to be investigated in future studies.

- Phase-volume changes. Volume changes (due to water extraction) need to be considered in process design.

- Cesium extraction. If not removed before hand, the behavior of $\mathrm{Cs}^{+}$in the process will need to be explored further so that the process can be operated in a manner in which the recovered $\mathrm{NaOH}$ is sufficiently free of ${ }^{137} \mathrm{Cs}$ to allow for its subsequent use. 


\section{Glossary}

$\begin{array}{ll}\text { DOE } & \text { U.S. Department of Energy } \\ \begin{array}{ll}\text { ESP } \\ \text { ESW }\end{array} & \begin{array}{l}\text { Efficient Separations and Processing Crosscutting Program } \\ \text { enhanced sludge washing }\end{array} \\ \text { HLW } & \text { high-level waste } \\ \text { ICP/AES } & \begin{array}{l}\text { inductively coupled plasma/atomic emission spectroscopy } \\ \text { IHLW }\end{array} \\ \text { LAW } & \text { low-activity waste } \\ \text { ORNL } & \text { Oak Ridge National Laboratory } \\ \text { PNNL } & \text { Pacific Northwest National Laboratory }\end{array}$




\section{Acknowledgments}

This work was funded by the U.S. Department of Energy (DOE) Office of Science and Technology through the Efficient Separations and Processing Crosscutting Program (ESP). The authors thank Jerry Harness and Jack Watson of the ESP and Phil McGinnis of the Tanks Focus Area. The authors also acknowledge Ted Pietrok and Marcus Glasper in the DOE Richland Operations Office.

The authors gratefully acknowledge W. C. Cosby, J. L. Draper, B. M. Rapko, S. M. Robinson, J. S. Watson, and M. C. Thompson for reviewing this document. The authors also thank C. L. Blair, W. F. Bonner, J. R. Andrie, and M. Larson for their project-management support.

Pacific Northwest National Laboratory is operated by Battelle for the U.S. Department of Energy under Contract DE-AC06-76RL01830. 


\section{Contents}

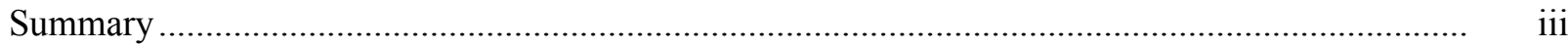

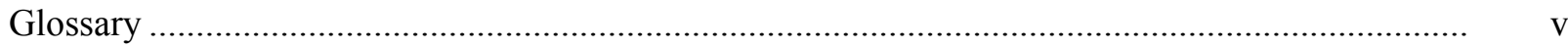

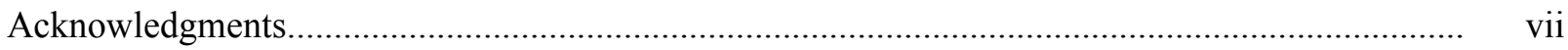

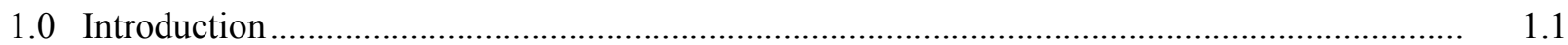

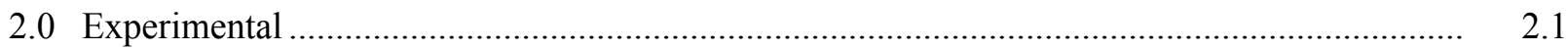

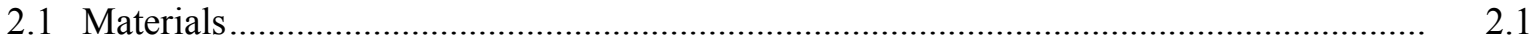

2.2 Test With S-110 Sludge Leaching Solution ...................................................................

2.3 Test With T-110 Sludge Leaching Solution..............................................................

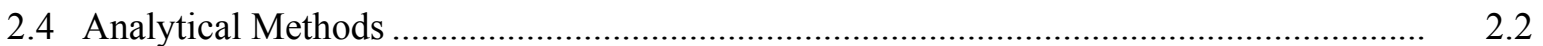

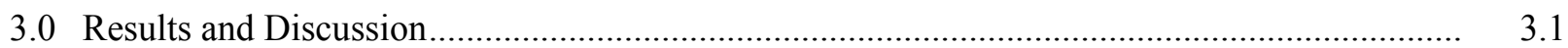

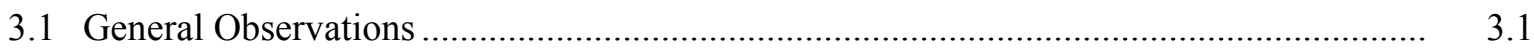

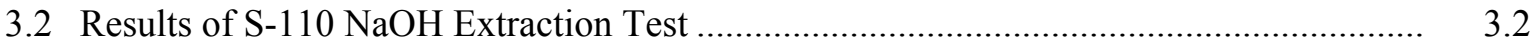

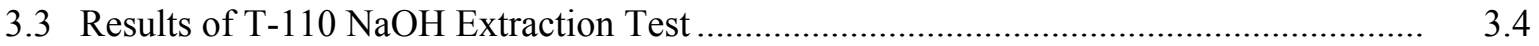

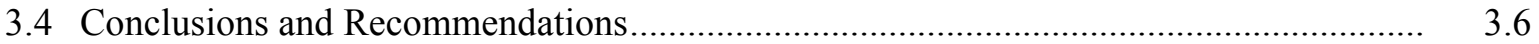

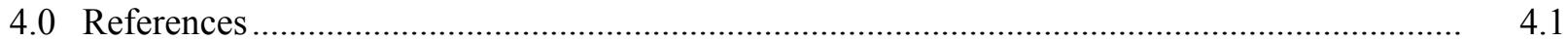




\section{Figures}

1.1. Deprotonation of Alcohols as a Function of Hydroxide Concentration and $\mathrm{pK}_{\mathrm{a}}$ :

a) from 0 to $0.1 \mathrm{M} \mathrm{NaOH}$ and b) from 0 to $10 \mathrm{M} \mathrm{NaOH}$.

3.1. Sodium and Hydroxide Behavior in the S-110 Pseudo Hydroxide Extraction Experiment. .....

3.2. Cesium and Sodium Distribution Coefficients In The Stripping Contacts

3.3. Sodium and Hydroxide Behavior in the T-110 Pseudo Hydroxide Extraction Experiment ......

\section{Tables}

2.1. Composition of the S-110 and T-110 Leachates Used in the Pseudo Hydroxide Extraction Experiments

2.2. Summary of $\mathrm{NaOH}$ Extraction Test With S-110 Sludge Leaching Solution

2.3. Summary of $\mathrm{NaOH}$ Extraction Test With $\mathrm{T}-110$ Sludge Leaching Solution

3.1. Volume Changes During $\mathrm{NaOH}$ Extraction Tests

3.2. Results of $\mathrm{NaOH}$ Extraction From S-110 Leachate

3.3. Results of $\mathrm{NaOH}$ Extraction From $\mathrm{T}-110$ Leachate 


\subsection{Introduction}

Since 1990, the primary mission at the U.S. Department of Energy's (DOE) Hanford Site has changed from producing plutonium to restoring the environment (National Research Council 2001). Large volumes of high-level radioactive wastes (HLW), generated during past Pu production and other operations, are stored in underground tanks onsite. The current plan for remediating the Hanford tank farms consists of waste retrieval, pretreatment, treatment (immobilization), and disposal. The tank wastes will be partitioned into high-level and low-activity fractions. The low-activity waste (LAW) will be processed to remove ${ }^{137} \mathrm{Cs}$ and ${ }^{99} \mathrm{Tc}$ (and ${ }^{90} \mathrm{Sr}$ and transuranic elements in selected cases), and then it will be immobilized in a glass matrix and disposed of by shallow burial onsite. The HLW will be immobilized in a borosilicate glass matrix; the resulting glass canisters will then be disposed of in a geologic repository (DOE/ORP 2001). Because of the expected high cost of HLW vitrification and geologic disposal, pretreatment processes will be implemented to reduce the volume of immobilized highlevel waste (IHLW).

Dilute hydroxide washing is the minimum pretreatment that would be performed on Hanford tank sludges. This method simply involves mixing the sludge with dilute ( $0.1 \underline{\mathrm{M}}$ or less) $\mathrm{NaOH}$ solution, then performing a solid/liquid separation. This is meant to remove water-soluble sludge components (mainly sodium salts) from the HLW stream. Dilute hydroxide is used rather than water to maintain the ionic strength high enough that colloidal suspensions are avoided.

Caustic leaching (sometimes referred to as enhanced sludge washing [ESW]) represents the baseline method for pretreating Hanford tank sludges. This process involves digesting the sludge solids with several molar (nominally $3 \mathrm{M}) \mathrm{NaOH}$ at elevated temperature $\left(80\right.$ to $100^{\circ} \mathrm{C}$ ). Caustic leaching is expected to remove a large fraction of the Al, which is present in large quantities in Hanford tank sludges. The Al will be removed by converting aluminum oxides/hydroxides to sodium aluminate. For example, boehmite and gibbsite are dissolved according to the following equations (Weber 1982).

$$
\begin{gathered}
\mathrm{AlOOH}(\mathrm{s})+\mathrm{NaOH}(\mathrm{aq}) \rightarrow \mathrm{NaAl}(\mathrm{OH})_{4}(\mathrm{aq})+\mathrm{H}_{2} \mathrm{O} \\
\mathrm{Al}(\mathrm{OH})_{3}(\mathrm{~s})+\mathrm{NaOH}(\mathrm{aq}) \rightarrow \mathrm{NaAl}(\mathrm{OH})_{4}(\mathrm{aq})+2 \mathrm{H}_{2} \mathrm{O}
\end{gathered}
$$

A significant portion of the $\mathrm{P}$ is also expected to be removed from the sludge by the metathesis of water-insoluble metal phosphates to insoluble hydroxides and soluble $\mathrm{Na}_{3} \mathrm{PO}_{4}$. An example of the iron(III) phosphate metathesis is described by Equation 1.3.

$$
\mathrm{FePO}_{4}(\mathrm{~s})+3 \mathrm{NaOH}(\mathrm{aq}) \rightarrow \mathrm{Fe}(\mathrm{OH})_{3}(\mathrm{~s})+\mathrm{Na}_{3} \mathrm{PO}_{4}(\mathrm{aq})
$$

Similar metathesis reactions can also occur for insoluble sulfate salts, allowing the removal of sulfate from the HLW stream.

Based on its known amphoteric behavior (Rai et al. 1987), Cr(III) was expected to be removed by caustic leaching according to the following equation: 


$$
\mathrm{Cr}(\mathrm{OH})_{3}(\mathrm{~s})+\mathrm{NaOH}(\mathrm{aq}) \rightarrow \mathrm{Na}\left[\mathrm{Cr}(\mathrm{OH})_{4}\right](\mathrm{aq})
$$

However, studies conducted at the Pacific Northwest National Laboratory (PNNL) have suggested that the behavior of $\mathrm{Cr}$ in the caustic leaching process is more complex (Lumetta et al. 1997), involving an oxidative pathway that leads to $\mathrm{Cr}(\mathrm{VI})$ in the leaching solutions.

Results from previous studies of the baseline Hanford sludge-washing and caustic-leaching process have been reported (Lumetta and Rapko 1994; Rapko et al. 1995, Lumetta et al. 1996a and 1996b, 1997, 1998, 2001, and 2002; Temer and Villarreal 1995, 1996, and 1997). Parametric leaching tests (Lumetta et al. 1998 and 2001) suggest considerable benefit could be gained by varying process conditions to optimize performance for specific batches of sludge processed. One such variable parameter is the hydroxide concentration. Increasing the hydroxide concentration is generally beneficial and results in increased $\mathrm{Al}$ and $\mathrm{Cr}$ removal and improved solution stability. However, increasing the hydroxide concentration would have a negative impact if the added $\mathrm{NaOH}$ were routed to the LAW stream; that is, the LAW mass would be significantly increased.

To enable the use of higher hydroxide concentrations during sludge leaching, without adversely affecting the LAW stream, we have proposed to recycle the $\mathrm{NaOH}$ by using a liquid-liquid extraction method. This method has been successfully demonstrated for the hydroxide recovery from an alkaline tank waste simulant (Chamblis et al. 2002) and is based on cation-exchange principles. A weakly acidic lipophilic reagent (HA) in the organic phase exchanges a proton for sodium ion at elevated $\mathrm{pH}$ values characteristic of alkaline tank waste. The extraction mechanism can be described by the following equilibrium reaction:

$$
\mathrm{Na}^{+}(\mathrm{aq})+\mathrm{OH}^{-}(\mathrm{aq})+\mathrm{HA}(\text { org }) \rightleftharpoons \mathrm{H}_{2} \mathrm{O}+\mathrm{NaA}(\text { org })
$$

The reverse hydrolysis reaction regenerates the neutral hydroxy acid in the organic phase and recovers sodium hydroxide in the stripping phase:

$$
\mathrm{NaA}(\text { org })+\mathrm{H}_{2} \mathrm{O} \rightleftharpoons \mathrm{Na}^{+}(\mathrm{aq})+\mathrm{OH}^{-}(\mathrm{aq})+\mathrm{HA}(\text { org })
$$

When used in tandem, the forward and reverse steps constitute a cyclic process affording the transfer of alkali metal hydroxide from an aqueous waste mixture into water. Because this method does not result in direct hydroxide extraction (rather it transfers hydroxide equivalents), it has been termed pseudo $\mathrm{NaOH}$ extraction.

To function efficiently for hydroxide recovery, HA must possess weak acidity (aqueous $\mathrm{pK}_{\mathrm{a}}$ ca. 9-14) so that contact of the loaded solvent with water readily regenerates the protonated form of the extractant (Chamblis et al. 2002). Figure 1.1 illustrates this point. When the $\mathrm{pK}_{\mathrm{a}}$ is between 9 and 12, HA is almost entirely deprotonated at hydroxide concentrations $>0.1 \mathrm{M}$. This characteristic allows for efficient $\mathrm{Na}$ extraction, but stripping (i.e., conversion back to the protonated form; equation 1.6) becomes more difficult as the $\mathrm{pK}_{\mathrm{a}}$ decreases. Nevertheless, even at $\mathrm{pK}_{\mathrm{a}}=9$, only $1 \%$ of $\mathrm{ROH}$ should be deprotonated in pure water $\left(\left[\mathrm{OH}^{-}\right]=10^{-7} \mathrm{M}\right)$, so recovery of $\mathrm{NaOH}$ should be feasible. ${ }^{(a)}$

(a) The preceding discussion assumes a single (aqueous) phase. However, the concepts can be assumed to extend to the two phase solvent extraction systems investigated in this work. 
This report describes the results of tests performed to demonstrate applicability of the pseudo $\mathrm{NaOH}$ extraction to the solutions generated by caustic leaching of actual Hanford tank sludge. As a prototype, $t$ octylphenol has been investigated as the extractant. This extractant presumably has a $\mathrm{pK}_{\mathrm{a}}$ similar to that of $t$-butylphenol, which has a $\mathrm{pK}_{\mathrm{a}}$ of 10.2 (Cohen and Jones 1963). So this extractant should have the properties discussed in the preceding paragraph. The solvent formulations used in this work also contained alkyl alcohols. The alkyl alcohols should not significantly contribute to the pseudo $\mathrm{NaOH}$ extraction due to their high $\mathrm{pK}_{\mathrm{a}}$ values. For example, the $\mathrm{pK}_{\mathrm{a}}$ for 1-octanol is reported to be 19.4 (Kreshkov et al. 1970). At $5 \mathrm{M} \mathrm{NaOH}$, only $5 \times 10^{-4} \%$ of the 1 -octanol would be deprotonated. 

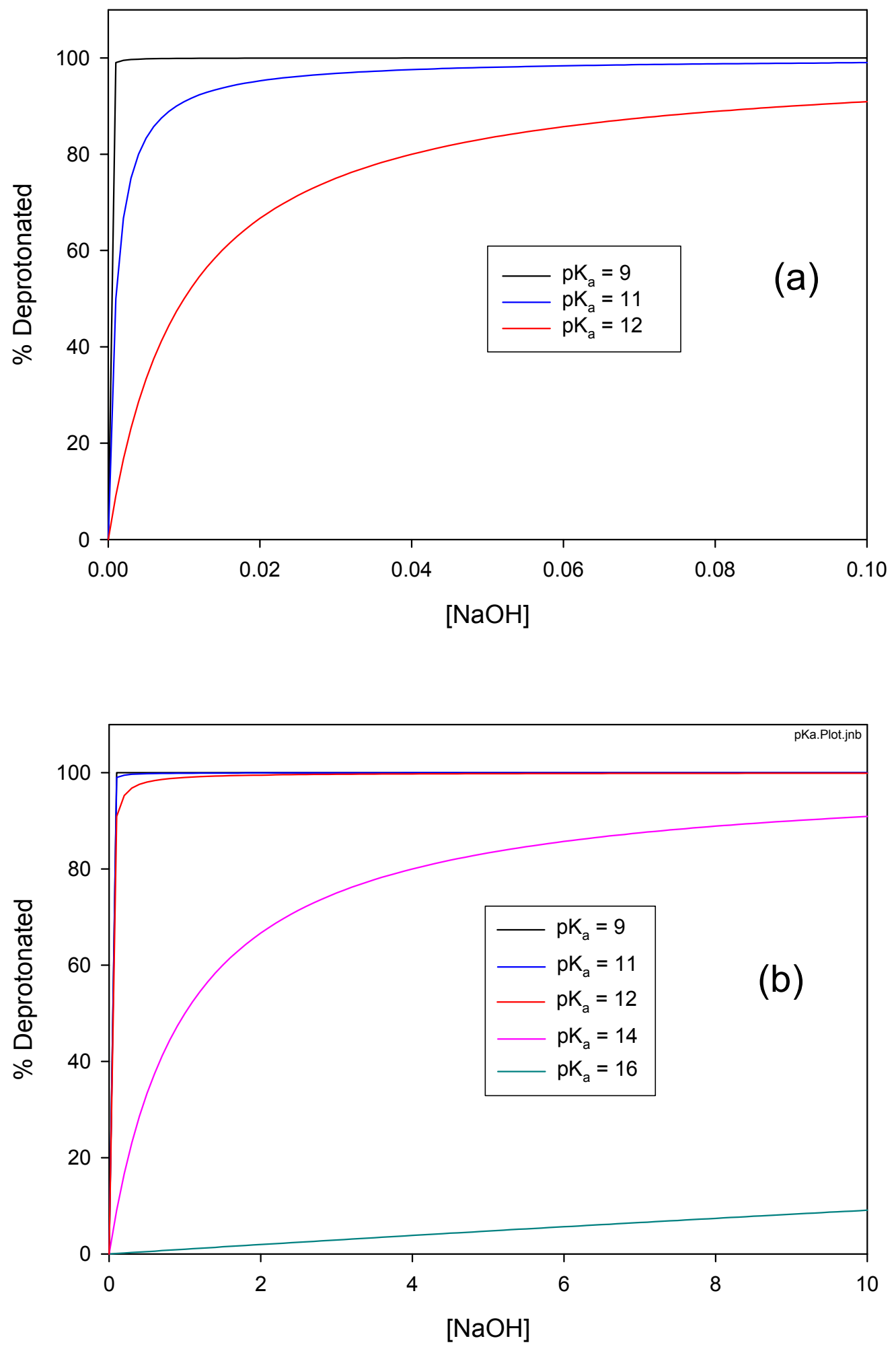

Figure 1.1. Deprotonation of Alcohols as a Function of Hydroxide Concentration and $\mathrm{pK}_{\mathrm{a}}$ : a) from 0 to $0.1 \mathrm{M} \mathrm{NaOH}$ and $b$ ) from 0 to $10 \mathrm{M} \mathrm{NaOH}$ 


\subsection{Experimental}

\subsection{Materials}

Commercially available 1-octanol, Isopar ${ }^{\circledR} \mathrm{L}, \operatorname{Exxal}{ }^{\circledR} 8,{ }^{(\text {a) }}$ and $t$-octylphenol were reagent-grade chemicals and were used as received. For stripping, distilled deionized $\left(18 \mathrm{M} \Omega \mathrm{cm}^{-1}\right.$, Barnstead Nanopure) water was used. All solvent extraction contacts were conducted in sealed glass vials. The S-110 and T-110 leachate solutions were generated during separate parametric sludge leaching tests (Lumetta et al. 2001 and 2002). Table 2.1 presents the concentrations of the major components in these solutions.

Table 2.2. Composition of the S-110 and T-110 Leachates Used in the Pseudo Hydroxide Extraction Experiments

\begin{tabular}{|l|r|r||}
\hline \multirow{2}{*}{ Component } & \multicolumn{2}{|c|}{ Concentration, mole/L } \\
\cline { 2 - 3 } & S-110 Leachate & T-110 Leachate \\
\hline $\mathrm{Al}$ & $1.65 \mathrm{E}-01$ & $6.17 \mathrm{E}-04$ \\
\hline $\mathrm{Cr}$ & $5.65 \mathrm{E}-03$ & $4.30 \mathrm{E}-03$ \\
\hline $\mathrm{Na}$ & $4.78 \mathrm{E}+00$ & $4.96 \mathrm{E}+00$ \\
\hline $\mathrm{P}$ & $5.17 \mathrm{E}-04$ & $1.67 \mathrm{E}-01$ \\
\hline $\mathrm{Si}$ & $<3 \mathrm{E}-03$ & $1.17 \mathrm{E}-01$ \\
\hline $\mathrm{OH}^{-}$ & 4.47 & 4.24 \\
\hline \hline${ }^{137} \mathrm{Cs}, \mu \mathrm{Ci} / \mathrm{mL}$ & $4.5 \mathrm{E}-01$ & $9.0 \mathrm{E}-03$ \\
\hline
\end{tabular}

\subsection{Test With S-110 Sludge Leaching Solution}

The feed solution used in this test was generated by leaching S- 110 solids with $5 \mathrm{M} \mathrm{NaOH}$ at $80^{\circ} \mathrm{C}$ for one week (Lumetta et al. 2001). Table 2.2 summarizes the liquid-liquid contacts performed during this test. In the two extraction tests, aqueous and organic phases were mixed by stirring at $60^{\circ} \mathrm{C}$; heating was accomplished by means of an aluminum heating block. After stirring for 30 minutes, the vial was removed from the heating block and shaken vigorously for one minute. The vial was then placed back in the heating block and stirred for 5 minutes. To separate the phases, the mixture was centrifuged for $\sim 1$ minute. The volume of each phase was estimated. ${ }^{(b)}$ The appropriate volume of organic phase was transferred to the S110-Strip1 vial, and the aqueous phase was sampled for analysis. In the case of S110Extr1, $6.0 \mathrm{~mL}$ of the aqueous phase was taken for contact S110-Extr2. The stripping contacts were performed by shaking the mixtures at ambient temperature for 2 minutes. Longer centrifuge times (30

(a) Isopar ${ }^{\circledR}$ L consists of a mixture of Isopar ${ }^{\circledR}$ affinic hydrocarbons. Exxal ${ }^{\circledR} 8$ is a mixture of branched 7- to 9-carbon alcohols, with 8-carbon alcohols being predominant. Both are available from ExxonMobil Chemical Company, Houston, Texas.

(b) To estimate the volumes, the height of each phase was measured with a ruler. Then deionized water was added to an identical vial to the same height and weighed. The volume was then calculated based on the weight of the water, assuming the density of water to be $1.0 \mathrm{~g} / \mathrm{mL}$. 
minutes) were used for the stripping contacts due to poor phase disengagement (as discussed in Section $3.1)$.

Table 2.2. Summary of $\mathrm{NaOH}$ Extraction Test With S-110 Sludge Leaching Solution

\begin{tabular}{|l|l|l||}
\hline Contact ID & \multicolumn{1}{|c|}{ Aqueous Phase } & \multicolumn{1}{c|}{ Organic Phase } \\
\hline S110-Extr1 & $7.5 \mathrm{~mL}$ feed solution & $7.5 \mathrm{~mL} \mathrm{1} \mathrm{M} t$-octylphenol in 1-octanol \\
\hline S110-Extr2 & $6.0 \mathrm{~mL}$ aqueous phase from S110-Extr1 & $6.0 \mathrm{~mL} \mathrm{1} \mathrm{M} t$-octylphenol in 1-octanol \\
\hline S110-Strip1 & $9.9 \mathrm{~mL}$ deionized water & $5.5 \mathrm{~mL}$ organic phase from S110-Extr1 + \\
& & $4.4 \mathrm{~mL}$ organic phase from S110-Extr2 \\
\hline S110-Strip2 & $8.0 \mathrm{~mL}$ deionized water & $8.0 \mathrm{~mL}$ organic phase from S110-Strip1 \\
\hline S110-Strip3 & $6.0 \mathrm{~mL}$ deionized water & $6.0 \mathrm{~mL}$ organic phase from S110-Strip2 \\
\hline
\end{tabular}

\subsection{Test With T-110 Sludge Leaching Solution}

The feed solution used in this test was generated by leaching T-110 solids with $5 \mathrm{M} \mathrm{NaOH}$ at $80^{\circ} \mathrm{C}$ for one week (Lumetta et al. 2002). Table 2.3 summarizes the liquid-liquid contacts performed during this test. Again, the extraction contact was performed at $60^{\circ} \mathrm{C}$. In this case, the phases were mixed by shaking for $1 \mathrm{~h}$ in a reciprocal shaker at $200 \mathrm{rpm}$. The shaker was equipped with a temperature-controlled aluminum heating block which was set at $60^{\circ} \mathrm{C}$. Immediately after removing from the heating block, the vial was vortex mixed for one minute and then centrifuged for $5 \mathrm{~min}$. The volume of each phase was estimated by weighing equal volumes of deionized water. ${ }^{(a)}$ The stripping contacts were performed by vortex mixing for $5 \mathrm{~min}$ at ambient temperature. Phases were separated by centrifuging for $5 \mathrm{~min}$ (see Section 3.1 for discussion of phase disengagement behavior).

Table 2.3. Summary of $\mathrm{NaOH}$ Extraction Test With T-110 Sludge Leaching Solution

\begin{tabular}{|c|c|c|}
\hline Contact ID & Aqueous Phase & Organic Phase \\
\hline T110-Extr1 & $3 \mathrm{~mL}$ feed solution & $\begin{array}{l}12 \mathrm{~mL} 1 \mathrm{M} t \text {-octylphenol in } 50 \% \text { Exxal } \AA \\
8 / 50 \% \text { Isopar } \AA \text { L }\end{array}$ \\
\hline T110-Strip1 & $10 \mathrm{~mL}$ deionized water & $10 \mathrm{~mL}$ organic phase from T110-Extr1 \\
\hline T110-Strip2 & $8 \mathrm{~mL}$ deionized water & $7 \mathrm{~mL}$ organic phase from T110-Strip1 \\
\hline T110-Strip3 & $5 \mathrm{~mL}$ deionized water & $5 \mathrm{~mL}$ organic phase from $\mathrm{S} 110$-Strip2 \\
\hline T110-Strip4 & $3 \mathrm{~mL}$ deionized water & $2.5 \mathrm{~mL}$ organic phase from S110-Strip3 \\
\hline
\end{tabular}

\subsection{Analytical Methods}

The free hydroxide concentration in the aqueous solutions was determined by titration with standard $\mathrm{HCl}$. Aliquots of the solution to be analyzed were diluted into $10 \mathrm{~mL}$ of deionized water. Calcium nitrate ( $0.1 \mathrm{~mL}$ of $2 \mathrm{M}$ solution) was added to the analyte solutions to remove carbonate ion. The resulting

(a) Estimate of the phase volumes for T110-Strip3 was inadvertently not done. Based on the minimal changes in phase volumes observed for T110-Strip2, it was assumed that no change in the volumes occurred for T110-Strip3. 
solutions were then titrated with $0.1 \mathrm{M} \mathrm{HCl}$. The titration was conducted using a Mettler DL-21 automatic titrator equipped with a combination Ross ${ }^{\circledR}$ Electrode (ATI Orion, Boston, Massachusetts).

Sodium, $\mathrm{Al}$, and $\mathrm{Cr}$ concentrations were determined by inductively-coupled plasma atomic emission spectroscopy. Cesium-137 was determined by gamma spectroscopy using an intrinsic germanium detector. 


\subsection{Results and Discussion}

\subsection{General Observations}

Workers at Oak Ridge National Laboratory (ORNL) have shown that significant extraction of water occurs during pseudo $\mathrm{NaOH}$ extraction with $t$-octylphenol, so this parameter was of interest in the tests performed here. This phenomenon results in changes in the relative phase volumes. Table 3.1 summarizes the volume changes that occurred in the S-110 and T-110 tests. Although the volume changes should be viewed as approximate, these data show the trend of a decrease in aqueous phase volume during extraction and a corresponding increase in the organic phase volume. The opposite is true during stripping as water is released back to the aqueous phase. These findings are consistent with observation that upon contact with water, dry 1-octanol solubilizes appreciable amount of water; the solubility of water in 1-octanol is $2.3 \mathrm{M}$ at $25^{\circ} \mathrm{C}$ (Westall, Johnson, and Dietz 1990). Aqueous and organic (1-octanol) volume changes upon equilibration have been investigated in detail as a function of the aqueous ionic strength and the phase ratio (Sun and Moyer 1995). At high ionic strength (5 M LiCl) and initial organic-to-aqueous ratio of unity, the aqueous phase volume change was only around $3 \%$. Thus, the large reduction of the sludge leachate volume observed in our experiments cannot be explained by the high water solubility in 1-octanol. Possible explanations for this phenomenon include: 1) transport of hydrated sodium ions into the 1-octanol phase, or 2) the formation of inverted micelles upon deprotonation of the phenol extractant, which could accommodate "free" water within the hydrophilic inverted micelle core. Further fundamental studies are needed to distinguish between these (or other) possibilities.

Table 3.1. Volume Changes During $\mathrm{NaOH}$ Extraction Tests

\begin{tabular}{|l|c|c|c|c|c|c|}
\hline \multirow{2}{*}{ Contact } & Initial Volume, mL & Final Volume, mL & Volume Change, $\mathbf{~ m L}$ \\
\cline { 2 - 7 } & Aqueous & Organic & Aqueous & Organic & Aqueous & Organic \\
\hline \multicolumn{7}{|c|}{ S-110 Test } \\
\hline Extraction 1 & 7.5 & 7.5 & 7.1 & 8.4 & -0.4 & 0.9 \\
\hline Extraction 2 & 6.0 & 6.0 & 5.1 & 6.1 & -0.9 & 0.1 \\
\hline Strip 1 & 9.9 & 9.9 & 9.9 & 9.9 & 0.0 & 0.0 \\
\hline Strip 2 & 8.0 & 8.0 & 8.9 & 7.2 & 0.9 & -0.8 \\
\hline Strip 3 & 6.0 & 6.0 & 6.5 & 5.7 & 0.5 & -0.3 \\
\hline \multicolumn{7}{|c|}{ T-110 Test } \\
\hline Extraction & 3.0 & 12.0 & 1.5 & 12.3 & -1.5 & 0.3 \\
\hline Strip 1 & 10.0 & 10.0 & 11.0 & 9.0 & 1.0 & -1.0 \\
\hline Strip 2 & 8.0 & 7.0 & 8.0 & 6.9 & 0.0 & -0.1 \\
\hline Strip 3 (a) & 5.0 & 5.0 & 5.0 & 5.0 & 0.0 & 0.0 \\
\hline Strip 4 & 3.0 & 2.5 & 3.1 & 3.1 & 0.1 & 0.6 \\
\hline $\begin{array}{l}\text { (a) Actual change in volume was not measured. Based on the minimal change } \\
\text { observed for Strip 2, it was assumed that the volumes did not change in Strip 3. }\end{array}$ \\
\hline
\end{tabular}


A number of observations can be made concerning phase disengagement. An interfacial crud layer ( $\sim 2 \mathrm{~mm}$ thick) formed in the first strip contact during the S-110 test. This had the appearance of an emulsion, rather than a solid. For the second S-110 strip step, both phases were cloudy after centrifuging for $5 \mathrm{~min}$ and were still somewhat cloudy after centrifuging for $30 \mathrm{~min}$. Similar behavior was seen in the third strip, except that the aqueous phase was clear after $30 \mathrm{~min}$ (organic was cloudy). The interfacial emulsion was not evident in the second and third S-110 strips. No interfacial emulsions were observed during the T-110 test, but the organic phases during stripping were generally cloudy after centrifuging for 5 min. The cloudiness decreased with subsequent stripping steps. These phenomena should be investigated as further solvent development proceeds.

Workers at ORNL have also shown that loading of the solvent (1 $\mathrm{M} t$-octylphenol in 1-octanol) to $1 \mathrm{M} \mathrm{Na}$ can be achieved, but high solvent viscosity, or even gelation, can occur at $25^{\circ} \mathrm{C}$. Conducting the extraction steps at $60^{\circ} \mathrm{C}$ alleviates this problem. The organic phase from the S-110 test did gel upon standing at ambient temperature; the T-110 extract showed less propensity to gel. The viscosity/gelation phenomenon does not occur during stripping with water; thus, these steps were performed at ambient temperature.

\subsection{Results of S-110 NaOH Extraction Test}

Table 3.2 and Figure 3.1 summarize the results of the pseudo $\mathrm{NaOH}$ extraction test with the S-110 leachate. The behavior of $\mathrm{OH}^{-}$in the extraction steps was essentially what would be expected. The hydroxide concentration in the aqueous phase decreased by one molar equivalent when contacted with an equal volume of $1 \mathrm{M} t$-octylphenol. In other words, the entire acidic capacity of the $t$-octylphenol was consumed during the extraction steps. The behavior of $\mathrm{Na}$ was consistent with the hydroxide behavior, with the organic phase Na concentrations $\sim 1 \mathrm{M}$ in both extraction contacts. During stripping, only 30$40 \%$ of the $\mathrm{Na}$ was transferred to the aqueous stripping phase during each stripping contact, with a cumulative of $73 \%$ of the extracted $\mathrm{Na}$ being stripped after three contacts with deionized water. 


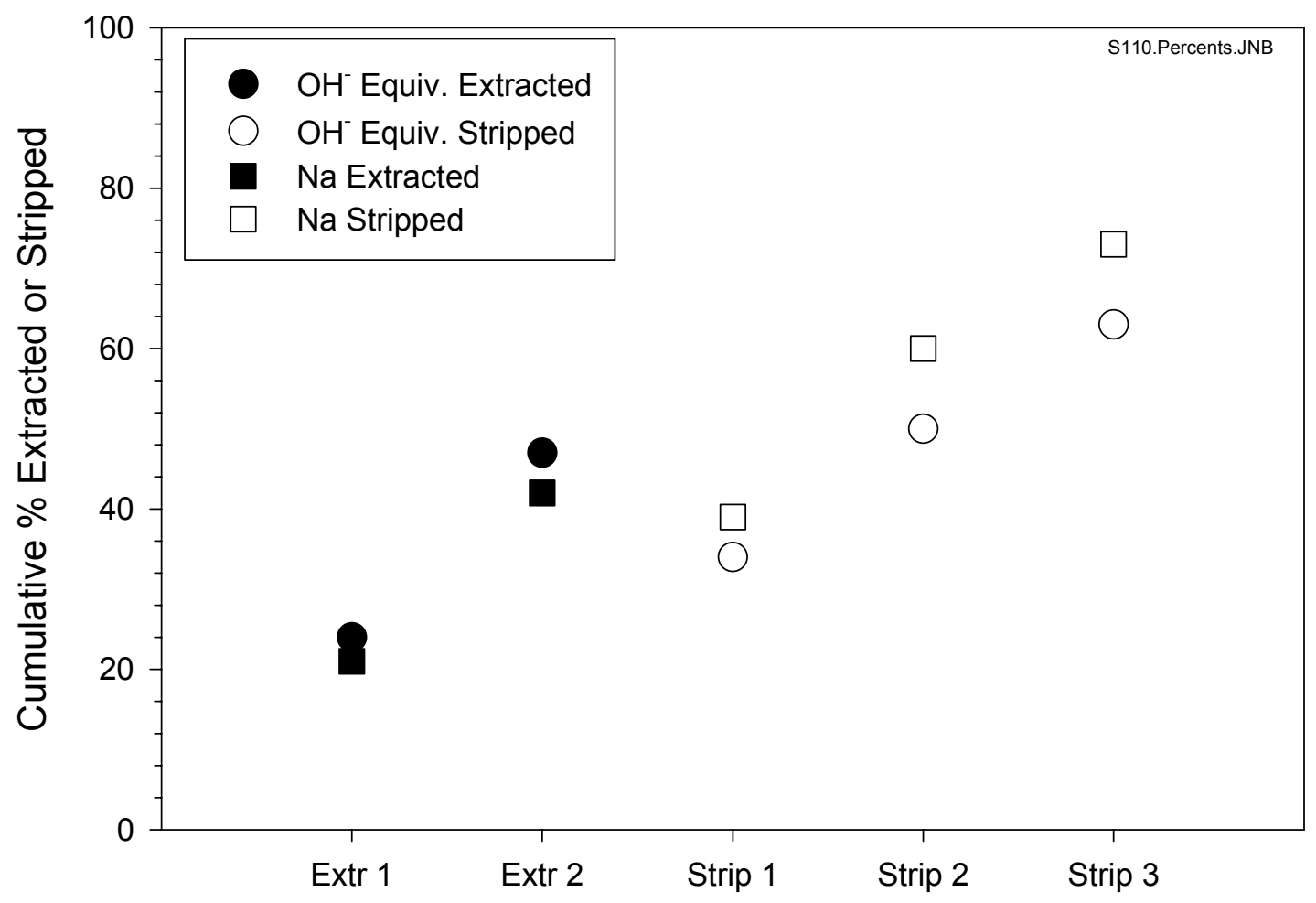

Figure 3.1. Sodium and Hydroxide Behavior in the S-110 Pseudo Hydroxide Extraction Experiment

Very little $\mathrm{Al}$ or $\mathrm{Cr}$ was extracted. The $\mathrm{K}^{+}$concentration in the S-110 leachate was below the detection limit $(<0.007 \mathrm{M})$ for the analyte solutions generated in this test. ${ }^{(a)}$ Cesium ion was the only interfering alkali metal ion followed in this experiment. Significant ${ }^{137} \mathrm{Cs}$ extraction was observed and stripping of the extracted Cs was difficult. Cesium extraction is not surprising due to its relatively low hydration energy. It would be expected that the more highly hydrated $\mathrm{Na}^{+}$ion would strip more readily than $\mathrm{Cs}^{+}$. Comparison of the $D_{\mathrm{Na}}$ and $D_{\mathrm{Cs}}$ values on the stripping stages (Figure 3.2) indicates that $\mathrm{Cs}^{+}$ has higher affinity for the organic phase confirming different stripping behavior of these ions. Values of $D_{\mathrm{Na}}$ increased slightly from strip 1 to strip 2 and leveled off at strip 3, while $D_{\mathrm{Cs}}$ values increased steadily from strip 1 to strip 3. Because of the desire to recycle the recovered $\mathrm{NaOH}$, the behavior of $\mathrm{Cs}$ in the psuedo $\mathrm{NaOH}$ extraction method deserves further investigation.

(a) Previous analysis of the S-110 leachate solution indicated the $\mathrm{K}$ concentration was about $0.002 \mathrm{M}$ (Lumetta et al. 2001). 


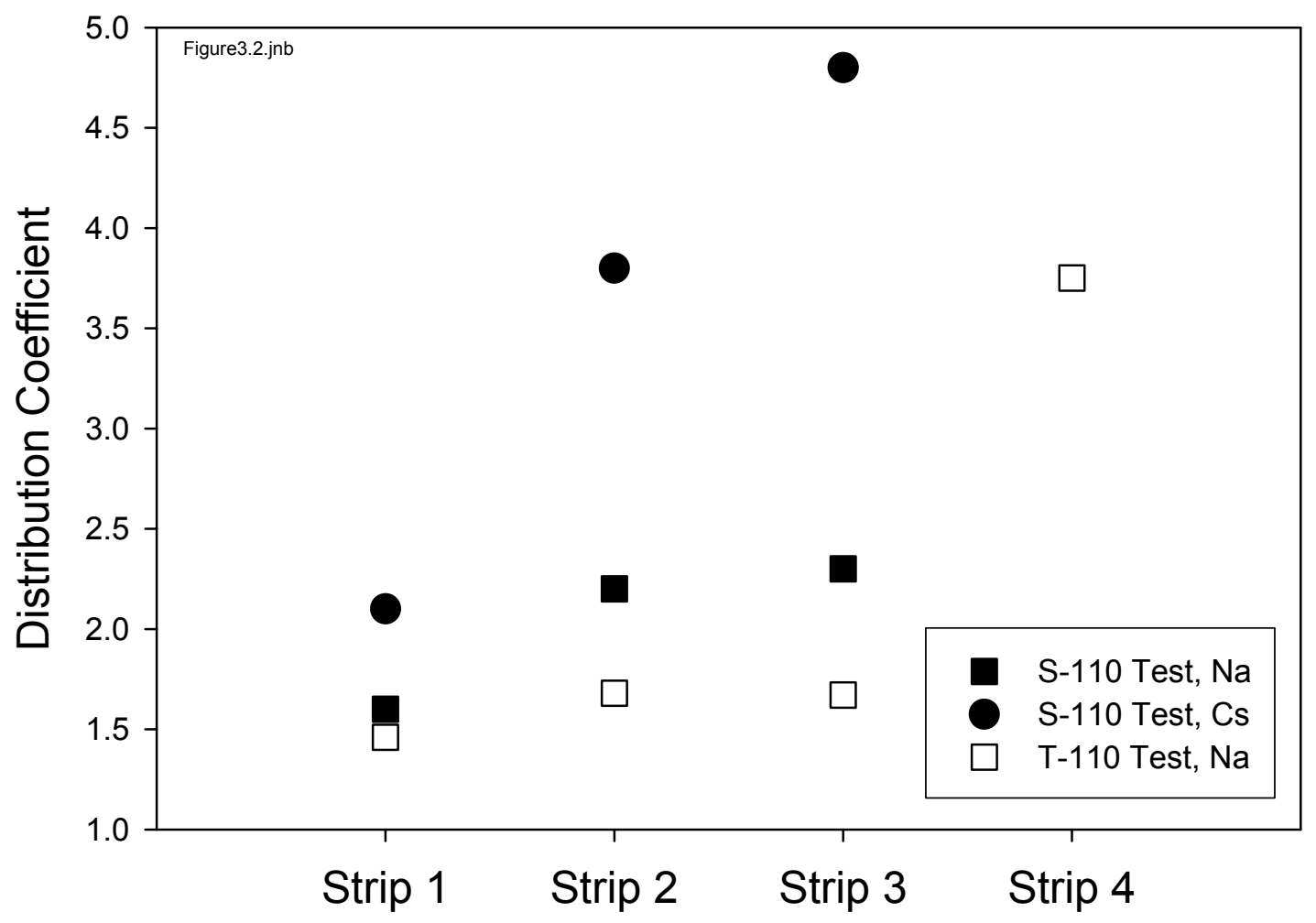

Figure 3.2. Cesium and Sodium Distribution Coefficients In The Stripping Contacts

\subsection{Results of T-110 NaOH Extraction Test}

Table 3.3 and Figure 3.3 summarize the results of the pseudo $\mathrm{NaOH}$ extraction test with the T-110 leachate. Consistent with the S-110 test, there was no discernable extraction of $\mathrm{Al}$ or $\mathrm{Cr}$. The ${ }^{137} \mathrm{Cs}$ content in the T-110 leachate was very low, so this component was not tracked in this test. Table 3.3 focuses on the two major components of interest $-\mathrm{Na}$ and $\mathrm{OH}^{-}$.

The $\mathrm{Na}$ and $\mathrm{OH}^{-}$results track each other fairly well. In the extraction contact, 74 to $79 \%$ of the "NaOH" was extracted. This corresponds to 84 to $92 \%$ of the acidic capacity of the $t$-octylphenol, which is less than the $100 \%$ capacity consumed in the S-110 test. This might be due to the different mixing methods used in the two tests. In the S-110 experiment, the two phases were mixed by stirring; in the T110 test, the mixtures were shaken, not stirred. Alternatively, the relative decrease in Na extraction efficiency might be due to a diluent effect.

The diluent can have a pronounced effect on the transport properties in solvent extraction systems (Allard et al. 1992). Whereas 1-octanol was used as the diluent in the S-110 test, a 50:50 vol.\% mixture of Exxal ${ }^{\circledR} 8$ and Isopar ${ }^{\circledR}$ L was used for the T-110 test. Exxal ${ }^{\circledR} 8$ consists of the mixture of the branched 
octyl alcohols and is expected to perform similar to 1-octanol. Addition of the highly non-polar kerosenelike Isopar ${ }^{\circledR} \mathrm{L}$, which lacks proton-donor properties, changes the solvation properties and effective acidity of the organic phase. This would be expected to result in a decrease in the extraction power of $t$ octylphenol. The slight improvement of the stripping efficiency (compare Figure 3.3 to Figure 3.1) supports the supposition that the effective acidity of the solvent is less in the 50:50 Exxal ${ }^{\circledR}$ 8/Isopar ${ }^{\circledR} \mathrm{L}$ system as compared to the 1-octanol system. Comparison of the corresponding $\mathrm{D}_{\mathrm{Na}}$ values (Figure 3.2) for each strip reveals higher sodium ion distribution into 1-octanol (S-110 experiment). After three stripping contacts, $80 \%$ of the $\mathrm{Na}$ was removed from the extractant phase. However, it appears that the stripping behavior levels off with successive stripping. Only an additional 5\% of the Na was stripped in the fourth stripping contact. In a process application, it may be necessary to employ an acidic wash to remove the remaining $\mathrm{Na}$ (and $\mathrm{Cs}$ ) from the organic phase prior to recycling the solvent.

Table 3.2. Results of $\mathrm{NaOH}$ Extraction From S-110 Leachate ${ }^{(a)}$

\begin{tabular}{|c|c|c|c|c|c|c|c|c|c|c|}
\hline \multirow[b]{3}{*}{ Contact } & \multicolumn{8}{|c|}{ Concentration, mole/L } & & \\
\hline & \multicolumn{2}{|c|}{ Sodium } & \multicolumn{2}{|c|}{ Hydroxide } & \multicolumn{2}{|c|}{ Aluminum } & \multicolumn{2}{|c|}{ Chromium } & \multicolumn{2}{|c|}{${ }^{137} \mathrm{Cs}, \mathrm{cpm} / \mathrm{mL}$} \\
\hline & Aq. & Org. & Aq. & Org. $^{(\mathbf{b})}$ & Aq. & Org. & Aq. & Org. & Aq. & Org. \\
\hline Feed & 4.78 & $\mathrm{~N} / \mathrm{A}$ & 4.47 & N/A & 0.165 & N/A & $5.65 \mathrm{E}-03$ & N/A & 3184 & N/A \\
\hline Extraction 1 & 3.97 & 0.9 & 3.57 & 1.0 & 0.1 & (c) & $6.21 \mathrm{E}-03$ & (c) & 2241 & 49 \\
\hline Extraction 2 & 3.45 & 1.0 & 2.95 & 1.0 & 0.212 & (c) & $7.35 \mathrm{E}-03$ & (c) & 1722 & 765 \\
\hline Strip 1 & 0.37 & 0.6 & 0.34 & 0.7 & 0.0027 & (c) & $5.8 \mathrm{E}-05$ & (c) & 272 & 595 \\
\hline Strip 2 & 0.18 & 0.4 & 5 & 0.6 & $<4.0 \mathrm{E}-5$ & (c) & $<8.0 \mathrm{E}-6$ & (c & 131 & 499 \\
\hline Strip 3 & 0.13 & 0.3 & 0.13 & 0.4 & $<4.0 \mathrm{E}-5$ & (c) & $<4.0 \mathrm{E}-6$ & (c) & 88 & 425 \\
\hline \multicolumn{11}{|c|}{$\begin{array}{l}\text { (a) Aqueous phase concentrations are from measure values; organic phase concentrations were } \\
\text { determined by mass balance calculations. } \\
\text { (b) The reported values for the organic phase are for "hydroxide equivalents" rather than hydroxide } \\
\text { ion per se. Hydroxide equivalents were calculated from the difference between the initial and final } \\
\text { aqueous phase hydroxide concentrations and the relative organic-to-aqueous volume ratios. } \\
\text { (c) Could not be determined--calculated values were negative. }\end{array}$} \\
\hline
\end{tabular}




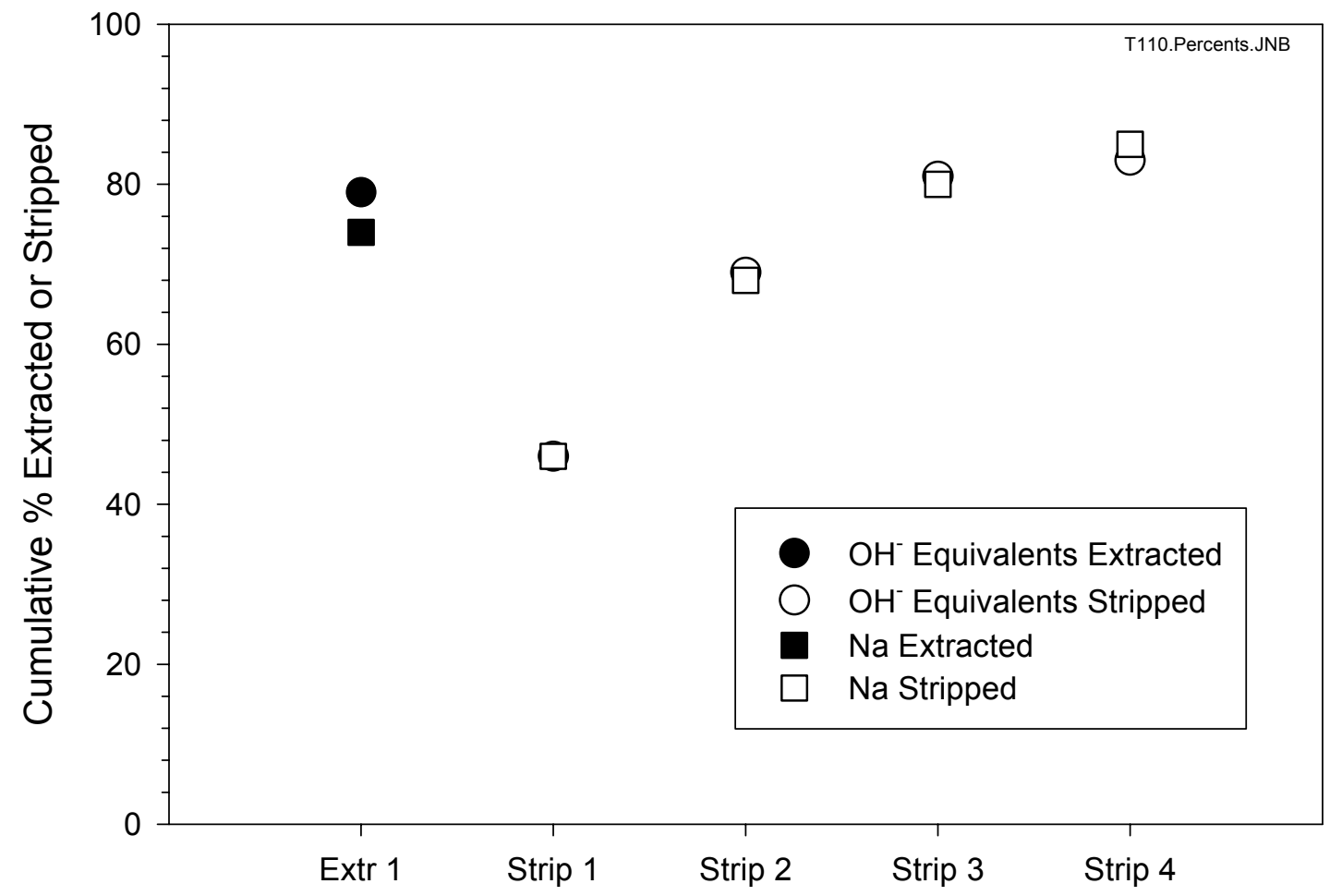

Figure 3.3. Sodium and Hydroxide Behavior in the T-110 Pseudo Hydroxide Extraction Experiment

\subsection{Conclusions and Recommendations}

The principle of recovering $\mathrm{NaOH}$ from Hanford tank sludge leaching solutions using solvent extraction has been demonstrated. The process involves neutralization of a lipophilic weak acid $(t-$ octylphenol was used in these experiments) by reaction with $\mathrm{NaOH}$ in the aqueous phase. This results in the transfer of $\mathrm{Na}$ into the organic phase. Contacting with water reverses this process, reprotonating the lipophilic weak acid and transferring $\mathrm{Na}$ back into the aqueous phase as $\mathrm{NaOH}$.

The work described here confirms the potential application of solvent extraction to recover and recycle $\mathrm{NaOH}$ from solutions generated by leaching Hanford tank sludges. It was demonstrated that $\mathrm{Na}^{+}$ is transferred from caustic leaching solution to the organic phase when contacted with $t$-octylphenol solutions. This was accompanied by a concomitant decrease in the aqueous-phase hydroxide ion concentration. Seventy to $80 \%$ of the extracted $\mathrm{Na}$ was recovered by three to four sequential contacts of the organic phase with water. Cesium was co-extracted by the procedure, but $\mathrm{Al}$ and $\mathrm{Cr}$ remained in the feed stream. 
However, a number of issues must be addressed before this technology can come to fruition. First, effective stripping of $\mathrm{Na}$ from the organic phase must be demonstrated. The results of the $\mathrm{T}-110$ test suggested that it might be difficult to get complete recovery of $\mathrm{Na}$ as $\mathrm{NaOH}$ by stripping with water. It may be necessary to employ an acid wash of the solvent to remove residual $\mathrm{Na}$ before the solvent can be recycled in the process. Alternatively, a lipophilic acid with aqueous $\mathrm{pK}_{\mathrm{a}}$ of about two units higher than $\mathrm{pK}_{\mathrm{a}}$ of $t$-octylphenol could be employed. Second, phase disengagement behavior is of concern especially in the stripping sections. Interfacial crud was observed in the S-110 stripping contacts and cloudy phases were seen during the T-110 stripping contacts. Phase disengagement depends on the chemical structure of the extractant and it might be beneficial to use an extractant with a sterically shielded functional group, so that it is less surface-active. Another way to improve phase disengagement is to increase the ionic strength of the stripping solution. The reasons for these phenomenon and means to avoid them need to be investigated in future studies. Third, the tendency for phase volume changes (due to water extraction) would need to be considered in process design. If not removed before hand, the behavior of $\mathrm{Cs}$ in the process will need to be explored further so that the process can be operated in a manner in which the recovered $\mathrm{NaOH}$ is sufficiently free of ${ }^{137} \mathrm{Cs}$ to allow for subsequent use.

Table 3.3. Results of $\mathrm{NaOH}$ Extraction From T-110 Leachate $^{(\mathrm{a})}$

\begin{tabular}{|c|c|c|c|c|}
\hline \multirow[b]{3}{*}{ Contact } & \multicolumn{4}{|c|}{ בConcentration, $\mathbf{M}$} \\
\hline & \multicolumn{2}{|c|}{ Sodium } & \multicolumn{2}{|c|}{ Hydroxide } \\
\hline & Aqueous & Organic & Aqueous & Organic $^{(\mathbf{b})}$ \\
\hline Feed & 4.96 & $\mathrm{~N} / \mathrm{A}$ & 4.24 & N/A \\
\hline Extraction 1 & 2.58 & 0.89 & 1.80 & 0.81 \\
\hline Strip 1 & 0.37 & 0.54 & 0.34 & 0.49 \\
\hline Strip 2 & 0.19 & 0.32 & 0.18 & 0.28 \\
\hline Strip 3 & 0.12 & 0.20 & 0.11 & 0.17 \\
\hline Strip 4 & 0.04 & 0.15 & 0.012 & 0.16 \\
\hline \multicolumn{5}{|c|}{$\begin{array}{l}\text { (a) Aqueous phase concentrations are from measure values; organic phase } \\
\text { concentrations were determined by mass balance calculations. There was } \\
\text { no discernable extraction of } \mathrm{Al}, \mathrm{Cr}, \mathrm{P} \text {, or } \mathrm{Si} \text { in this system. } \\
\text { (b) The reported values for the organic phase are for "hydroxide equivalents" } \\
\text { rather than hydroxide ion per se. }\end{array}$} \\
\hline
\end{tabular}




\subsection{References}

Allard B, GR Choppin, C Musikas, and J Rydberg. 1992. "Systematics of Solvent Extraction," in Principles and Practices of Solvent Extraction, J. Rydberg, C. Musikas, G. R. Choppin, eds. Marcel Dekker, New York, New York; pp. 223-224.

Chamblis CK, TJ Haverlock, PV Bonnesen, NL Engle, and BA Moyer. 2002. "Selective Separation of Hydroxide from Alkaline Nuclear Tank Waste by Liquid-Liquid Extraction With Weak Hydroxy Acids," Environ. Sci. Technol., 36:1861-1867.

Cohen LA, and WM Jones. 1963. "A Study of Free Energy Relationships in Hindered Phenols. Linear Dependence for Solvation Effects in Ionization," Aust. J. Chem., 85:3397-3406.

Kreshkov AP, NSh Aldarova, NT Smolova, and AI Ryaguzov. 1970. "An Estimate of the Autoprotolysis Constants of Non-aqueous Solvents,” Russ. J. Phys. Chem., 44:628-629.

Lumetta GJ, and BM Rapko. 1994. Washing and Alkaline Leaching of Hanford Tank Sludges: A Status Report, PNL-10078, Pacific Northwest National Laboratory, Richland, Washington.

Lumetta GJ, BM Rapko, MJ. Wagner, J Liu, and YL Chen. 1996a. Washing and Caustic Leaching of Hanford Tank Sludges: Results of FY 1996 Studies, PNNL-11278, Rev. 1, Pacific Northwest National Laboratory, Richland, Washington.

Lumetta GJ, MJ Wagner, FV Hoopes, and RT Steele. 1996b. Washing and Caustic Leaching of Hanford Tank C-106 Sludge, PNNL-11381, Pacific Northwest National Laboratory, Richland, Washington.

Lumetta GJ, IE Burgeson, MJ Wagner, J Liu, and YL Chen. 1997. Washing and Caustic Leaching of Hanford Tank Sludges: Results of FY 1997 Studies, PNNL-11636, Pacific Northwest National Laboratory, Richland, Washington.

Lumetta GJ, BM Rapko, J Liu, DJ Temer, and RD Hunt. 1998. Washing and Caustic Leaching of Hanford Tank Sludges: Results of FY 1998 Studies, PNNL-12026, Pacific Northwest National Laboratory, Richland, Washington.

Lumetta GJ, KJ Carson, LP Darnell, LR Greenwood, FV Hoopes, RL Sell, SI Sinkov, CZ Soderquist, MW Urie, and JJ Wagner. 2001. Caustic Leaching of Hanford Tank S-110 Sludge, PNNL-13702, Pacific Northwest National Laboratory, Richland, Washington.

Lumetta, GJ, LP Darnell, PA Garza, LR Greenwood, BM Oliver, DE Rinehart, DR Sanders, CZ Soderquist, T Trang-Le, MW Urie, and JJ Wagner. 2002. Caustic Leaching of Hanford Tank T-110 Sludge, PNNL-13956, Pacific Northwest National Laboratory, Richland, Washington.

National Research Council. 2001. Research Needs For High Level Waste Stored In Tanks And Bins At U.S. Department of Energy Sites, National Academy Press, Washington, DC. 
Rai D, M Sass, and DA Moore. 1987. "Chromium(III) Hydrolysis Constants and Solubility of Chromium(III) Hydroxide.” Inorg. Chem., 26: 345-349.

Rapko BM, GJ Lumetta, and MJ Wagner. 1995. Washing and Caustic Leaching of Hanford Tank Sludges: Results of FY 1995 Studies, PNL-10712, Pacific Northwest Laboratory, Richland, Washington.

Sun Y, and BA Moyer. 1995. "Phase Volume Changes Accompanying Water Extraction from Aqueous Electrolyte Solutions by 1-Octanol," Solvent Extr. Ion Exch., 13:243-252.

Temer DJ, and R Villarreal. 1995. Sludge Washing and Alkaline Leaching Tests on Actual Hanford Tank Sludge: A Status Report, LAUR-95-2070, Los Alamos National Laboratory, Los Alamos, New Mexico.

Temer DJ, and R Villarreal. 1996. Sludge Washing and Alkaline Leaching Tests on Actual Hanford Tank Sludge: FY 1996 Results, LAUR-96-2839, Los Alamos National Laboratory, Los Alamos, New Mexico.

Temer DJ, and R Villerreal. 1997. Sludge Washing and Alkaline Leaching Tests on Actual Hanford Tank Sludge: FY 1997 Results, LAUR-97-2889, Los Alamos National Laboratory, Los Alamos, New Mexico.

U.S. Department of Energy/Office of River Protection (DOE/ORP). 2001. River Protection Project Project Management Plan, DOE/ORP-2000-06, Richland, Washington.

http://www.hanford.gov/orp/documents/orp-2000-06/index.html\#P572_20332

Weber EJ. 1982. Aluminum Hydroxide Dissolution in Synthetic Sludges, DP-1617, Savannah River Laboratory, Aiken, South Carolina.

Westall JC, Johnson CA., and Zhang W. 1990. "Distribution of $\mathrm{LiCl}, \mathrm{NaCl}, \mathrm{KCl}, \mathrm{HCl}, \mathrm{MgCl}_{2}$, and $\mathrm{CaCl}_{2}$ Between Octanol and Water," Environ. Sci. Technol., 24, 1803-1810. 
PNNL-14026

\section{Distribution}

No. of

Copies

OFFSITE

Gilbert Brown

Oak Ridge National Laboratory

P.O. BOX 2008

Oak Ridge, Tennessee 37831-6119

Kurt Gerdes

U.S. Department of Energy

Office of Technology Systems

EM-53 Cloverleaf 1186

U.S. Department of Energy

PO Box 23865

Germantown, Maryland 20026-3865

Jerry Harness

U.S. Department of Energy

Oak Ridge Operations Office

200 Administration Road

Oak Ridge, Tennessee 37830

Tammy Haverlock

Oak Ridge National Laboratory

P.O. Box 2008

Oak Ridge, Tennessee 37831-6119
No. of

Copies

OFFSITE

Phil McGinnis

Oak Ridge National Laboratory

P.O. Box 2008

Oak Ridge, Tennessee 37831-6223

Bruce Moyer

Oak Ridge National Laboratory

P.O. Box 2008

Oak Ridge, Tennessee 37831-6119

John Swanson

1318 Cottonwood

Richland, Washington

Major Thompson

Westinghouse Savannah River Co.

773-A, C140

Aiken, South Carolina 29808

Jack Watson

Oak Ridge National Laboratory

P.O. Box 2008

Oak Ridge, Tennessee 37831-6178 
PNNL-14026

No. of

Copies

\section{ONSITE}

4 DOE Richland Operations Office

R. Carreon

J. Cruz

B.M. Mauss

T.P. Pietrok

3 Bechtel

R. Peterson

P. Rutland

$2 \quad \mathrm{CHG}$

A.-M. Choho

K.A. Gasper
No. of

Copies

\section{ONSITE}

$37 \quad$ Pacific Northwest National Laboratory

TFA Technical Team Office (8) K9-69

W.F. Bonner (5) K9-14

W.C. Cosby K7-62

D.E. Kurath P7-28

T.G. Levitskaia P7-22

G.J. Lumetta (20) P7-22

H4-02

$\mathrm{H} 4-02$

B.M. Rapko

P7-25
H6-22

L4-07

Distr. 2 